\title{
Global Precipitation: Means, Variations and Trends During the Satellite Era (1979-2014)
}

\author{
Robert F. Adler ${ }^{1} \cdot$ Guojun $_{\text {Gu}}{ }^{1} \cdot$ Matthew Sapiano $^{1} \cdot$ \\ Jian-Jian Wang ${ }^{1}$ George J. Huffman ${ }^{2}$
}

Received: 28 November 2016/Accepted: 18 May 2017/Published online: 6 June 2017

(C) The Author(s) 2017. This article is an open access publication

\begin{abstract}
Global precipitation variations over the satellite era are reviewed using the Global Precipitation Climatology Project (GPCP) monthly, globally complete analyses, which integrate satellite and surface gauge information. Mean planetary values are examined and compared, over ocean, with information from recent satellite programs and related estimates, with generally positive agreements, but with some indication of small underestimates for GPCP over the global ocean. Variations during the satellite era in global precipitation are tied to ENSO events, with small increases during El Ninos, and very noticeable decreases after major volcanic eruptions. No overall significant trend is noted in the global precipitation mean value, unlike that for surface temperature and atmospheric water vapor. However, there is a pattern of positive and negative trends across the planet with increases over tropical oceans and decreases over some middle latitude regions. These observed patterns are a result of a combination of inter-decadal variations and the effect of the global warming during the period. The results reviewed here indicate the value of such analyses as GPCP and the possible improvement in the information as the record lengthens and as new, more sophisticated and more accurate observations are included.
\end{abstract}

Keywords Satellite-based precipitation · Precipitation climatology · Global precipitation variability $\cdot$ Change

\section{Introduction}

Precipitation has been measured across the globe at various locations for centuries, beginning with simple and then more complex surface gauges. As the record at individual locations and over regions lengthened, long-term means (climatologies) were calculated

Robert F. Adler

radler@umd.edu

1 Earth System Science Interdisciplinary Center, University of Maryland, 5825 University Research Court, Suite 4001, College Park, MD 20740, USA

2 NASA Goddard Space Flight Center, Code 612, 8800 Greenbelt Road, Greenbelt, MD 20771, USA 
and seasonal and inter-annual variations at those locations were examined. Over many land areas, especially populated areas, these became very valuable to understand the climatology of precipitation across the globe. Over oceans, precipitation information was originally limited to islands and ships. Before the advent of satellites, global climatologies were constructed from the gauges over land and estimates of precipitation based on shipboard weather observations (e.g., Jaeger 1983). With satellite-based precipitation estimates available in the latter part of the twentieth century, efforts were made to provide analyses of monthly precipitation estimates combining the best observations over the entire globe with techniques to produce a consistent record during the period. The Global Precipitation Climatology Project (GPCP) was formed by the World Climate Research Program (WCRP) over 30 years ago in order to assess the long-term mean or climatology globally and regionally and improve our knowledge of variations of precipitation at various time and space scales (Arkin and Xie 1994). The GPCP monthly product (Adler et al. 2003; Huffman et al. 2009) is the basis for this review of the climatology and large-scale variations of precipitation during the satellite era (1979-2014).

Knowledge of the magnitude of global (and large-scale regional) precipitation and how it varies on different time scales is important for many reasons, including understanding global and regional water and energy balances, answering questions related to water resources for humans and agriculture and in order to better understand how environmental changes can affect this critical parameter.

In this study, we utilize the GPCP monthly analysis as a basis for reviewing the magnitudes and variations of precipitation during the last 36 years. One focus is the comparison of the GPCP global and tropical long-term means with shorter period records from new satellite observations such as CloudSat and TRMM. Long-term trends of global and regional precipitation and the impacts of volcanoes and ENSO on global means are also explored. Residual precipitation trends (with volcanoes and ENSO effects removed) are related to temperature and water vapor trends to better understand global warming relations, including regional precipitation trends.

\section{Data Sets}

The monthly precipitation data from the GPCP product (version 2.3) is applied in this study. This is a community-based analysis of global precipitation under the auspices of the World Climate Research Program (WCRP). Archived on a global $2.5^{\circ} \times 2.5^{\circ}$ grid, the data set covers the period starting in 1979 and is produced by merging a variety of data sources, including passive microwave-based rainfall retrievals from the special sensor microwave/imager (SSM/I) and the special sensor microwave imager sounder (SSMIS), infrared (IR) rainfall estimates from geostationary and polar-orbiting satellites, and surface rain gauges. The passive microwave data dominate over tropical and mid-latitude oceans and are also used over land. For example, over most of the period the ocean estimates (up to $40-50^{\circ}$ latitude) are driven by passive microwave estimates using SSM/I and more recently SSMIS data, with IR data being used to increase sampling and therefore smoothness and to help incorporate the diurnal cycle. At higher latitudes, over both ocean and land, empirical precipitation estimates from temperature-moisture sounders are utilized. Over land, at all latitudes where available, the gauge information (adjusted for undercatch) is utilized and dominates where gauge spacing is dense. Although many of the input data sets are now available on finer spatial scales, the $2.5^{\circ} \times 2.5^{\circ}$ analysis resolution 
allows for easier incorporation of historical data sets and is still commensurate with a monthly time scale. However, development of a next generation of the GPCP analysis is underway and will be at a finer spatial scale $\left(\sim 1^{\circ}\right)$. The combination procedures are designed to harness the strengths of individual inputs, specifically in terms of bias reduction (Adler et al. 2003; Huffman et al. 2009). The GPCP version 2.3 has recently been released and corrects some small inter-calibration and analysis errors that increase ocean precipitation somewhat compared to the previous version 2.2 , especially in middle latitudes during the last decade of analysis. The new version also includes a new version 7 full data monthly gauge analysis from the Global Precipitation Climatology Centre (GPCC) of the Deutscher Wetterdienst (DWD) in Germany. More details on version 2.3 can be found at http://gpcp.umd.edu/.

Recently, there have been new mission entrants into precipitation estimation from space. These include the Tropical Rainfall Measuring Mission (TRMM) (e.g., Kummerow et al. 2000) and CloudSat (Stephens et al. 2002) mission. TRMM carries both a precipitation radar (PR) at $14 \mathrm{GHz}$ and a TRMM microwave imager (TMI). CloudSat is a higher-frequency radar $(94 \mathrm{GHz})$ that is valuable for detecting light precipitation, more dominant at higher latitudes. Studies using these new data are utilized here to compare with GPCP mean values for comparison over ocean (e.g., Huffman et al. 2007). Results from the Global Precipitation Measurement (GPM) mission launched in 2014 (Hou et al. 2014) are not included here as retrieval algorithms are still maturing and mean estimates are still being evaluated.

The NASA-GISS surface temperature anomaly field (1880-present) is applied to examine temperature variations/changes due to its coverage over global land and ocean (Hansen et al. 1999). The data set combines the NOAA Global Historical Climatology Network (GHCN) v3 adjusted monthly mean temperature data over land augmented by Antarctic data collated by the UK Scientific Committee on Antarctic Research (SCAR) and the NOAA Extended Reconstructed Sea Surface Temperature (ERSST) v4 data (Smith et al. 2008; Huang et al. 2015). It is archived on a global $2^{\circ} \times 2^{\circ}$ grid and re-gridded to the GPCP grids. The temperature data derived using the $1200-\mathrm{km}$ smoothing level are used here.

The version-6 monthly special sensor microwave/imager (SSM/I) columnar water vapor products from the remote sensing systems (RSS) are used to describe the variations in oceanic precipitable water. The data cover the post-1987 period and are combined from several inter-calibrated satellite retrievals (Wentz 1997). For the post-2009 period, the version-7 special sensor microwave imager sounder (SSMIS) products are used. Simple inter-comparisons indicate that the SSMIS data are generally consistent with the SSM/I retrievals.

\section{Precipitation Climatology}

\subsection{Spatial and Seasonal Variations}

The long-term mean map of annual mean precipitation (Fig. 1a) for the satellite era (1979-2014) displays the usual dramatic features, including the Inter-Tropical Convergence Zone (ITCZ) across the Pacific Ocean and over the Atlantic and Indian Oceans and the land areas of Africa, the Maritime continent and South America. The South Pacific Convergence Zone (SPCZ) extending from the equatorial regions southeastward across the south Pacific Ocean is also very evident, along with a similar feature in the South Atlantic, extending from South America. The subtropical minima along the latitudes of $20^{\circ}$ are 
(a)

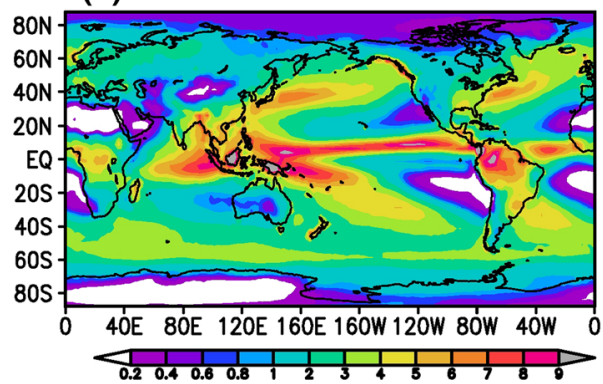

(b)

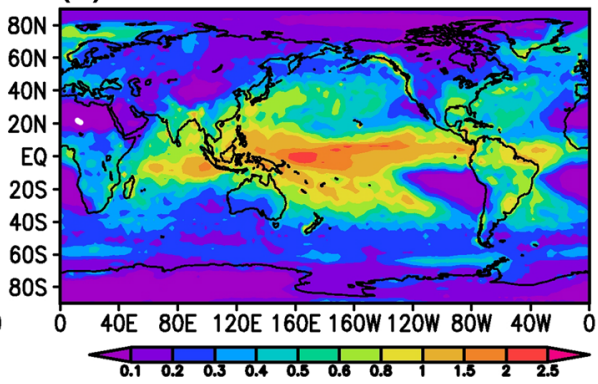

Fig. 1 a GPCP climatological mean precipitation (mm/day) during 1979-2014, and b standard deviations (mm/day) of annual precipitation anomalies

located with prominent deserts of those regions and dry areas of the eastern regions of the oceans at that latitude. In mid-latitudes of the northern hemisphere, rainfall maxima along and off the east coasts of the continents are noted extending northeastward, although in the mid-latitudes of the southern hemisphere, a weaker, but continuous precipitation maximum is observed circling the hemisphere.

Figure 1 depicts a long-term mean of a highly and rapidly varying variable and corresponding standard deviations of annual mean anomalies that are dominated by ENSOrelated inter-annual variability. There are significant variations even on the seasonal scale (Fig. 2). Over both the ocean and land, there is the seasonal thermal inertia process operating, with a larger amplitude of latitudinal variation over land. The areas of subtropical minima and mid-latitude maxima also evidence seasonal variation in their magnitudes and positions. For more examples of GPCP seasonal maps and variations, and latitudinal distributions, see figures in GPCP description papers (Adler et al. 2003; Huffman et al. 2009; Adler et al. 2012).

\subsection{Global and Tropical Mean Precipitation}

Averaging over the entire period of the GPCP record and pole to pole, the grand total estimate is $2.69 \mathrm{~mm} /$ day (Table 1) with an estimated error of approximately $\pm 7 \%$ based on the variation among estimates from a number of other products (see Adler et al. 2012). The ocean and land totals are 2.89 and $2.24 \mathrm{~mm} /$ day, respectively. Factoring in the difference in area between ocean and land over the globe, it can easily be seen that more than 2.5 times as much precipitation by volume falls over ocean as does over land.

Because determination of ocean precipitation is very largely dependent on satellitebased estimates, it is critical to determine our confidence in those estimates to understand the gross magnitude of our planet's water cycle. Researchers have used a variety of data sets, including satellite data sets (and models) to estimate the components of the water cycle (precipitation, evaporation, transport, etc.) to try and balance, or "close" the water cycle on a global or large regional (e.g., continental or ocean basin) scale. For example, Trenberth et al. (2009) adjusted the GPCP value upward by $5 \%$ to achieve a global water balance. In another, more recent, example, Rodell et al. (2015) examined the mean global water cycle for the first decade of the twenty-first century by using various satellite-based and conventional data sets, with reanalysis used to fill certain gaps. Initially, they used the magnitudes of the components as given by the means over the first decade of the twenty- 
(a) GPCP (DJF)

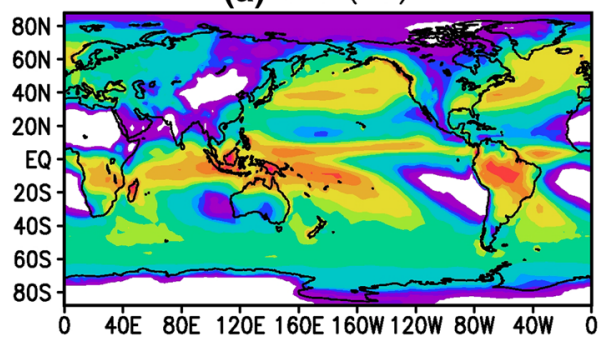

(c) GPCP (JJA)

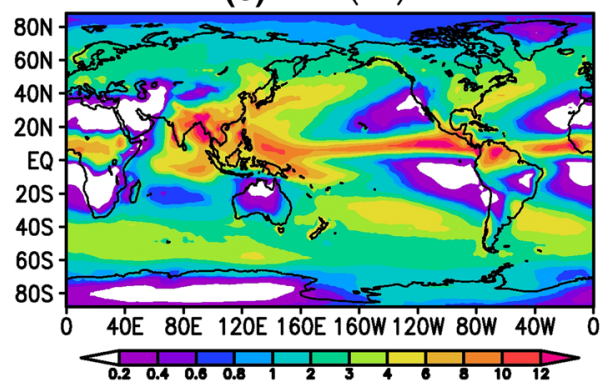

(b) GPCP (MAM)

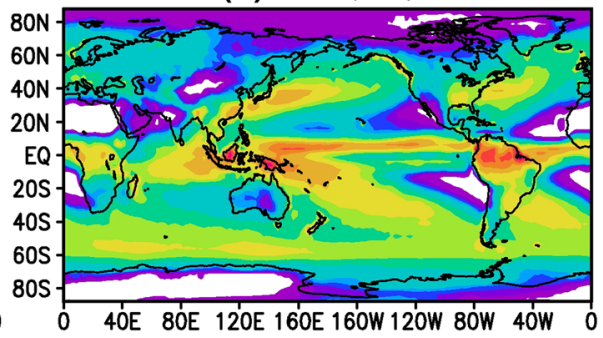

(d) GPCP (SON)

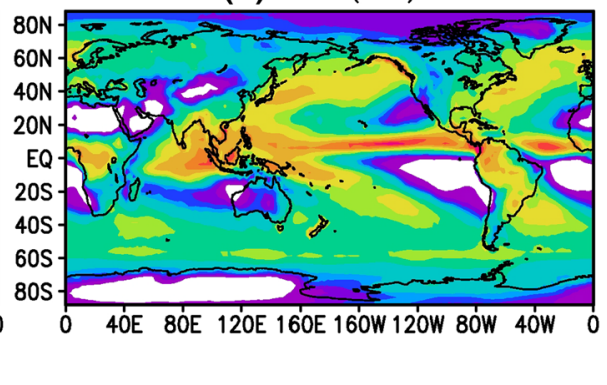

Fig. 2 Seasonal mean GPCP precipitation (mm/day). a December-January-February (DJF), b MarchApril-May (MAM), c June-July-August (JJA) and d September-October-November (SON)

Table 1 Global mean GPCP precipitation ( $P$, mm/day) during 1979-2014 and estimated errors $(\sigma)$

\begin{tabular}{llll}
\hline & Ocean & Land & Land + Ocean \\
\hline$P$ & 2.89 & 2.24 & 2.69 \\
$\sigma$ & 0.29 & 0.16 & 0.25 \\
\hline
\end{tabular}

first century. But the study then used an objective method to adjust the various component magnitudes to achieve closure, based on the magnitude of the estimated errors for each of the different data sets. The earlier V2.2 GPCP regional and global means were used in this exercise, and the budget closure procedure required that the mean global precipitation over that period from GPCP had to be increased by $5 \%$ over ocean and about $1 \%$ over land. The GPCP V2.3 mean value over ocean is slightly larger than the V2.2 value, so a smaller adjustment would have been necessary if it had been used instead. On the other hand, Stephens et al. (2012) argued that the GPCP value must be increased by roughly $15 \%$ to balance the energy budget. However, L'Ecuyer et al. (2015), in the companion energy budget analysis paper to the Rodell et al. (2015) water cycle study, found an energy balance using the same GPCP values as Rodell et al. These GPCP adjustments (up to 5\% over ocean) fall within the estimated errors for GPCP (Adler et al. 2012) and give some confidence that the GPCP global-scale magnitudes are close to the actual values, or at least fit comfortably with the estimates of the other water cycle components. The very small adjustment over land reflects the value of the gauge data (Schneider et al. 2014) and the careful analyses thereof in GPCP, before its blending with the satellite data. It should be remembered, however, that the final GPCP over-land precipitation analyses contain an 
adjustment for gauge under-catch and are therefore slightly larger than straight gaugebased estimates.

So, how do the estimates from GPCP compare in terms of very large-scale means to these new estimates involving TRMM and CloudSat? First, we will focus on the tropics, and on the oceans. The tropics are important because a large fraction of global precipitation falls in the low-latitude region. And, oceans are critical, because of the lack of simple, but relatively accurate, rain gauge observations. For the ocean area between $35^{\circ} \mathrm{N}$ and $35^{\circ} \mathrm{S}$, the GPCP numbers compare quite closely with those of TRMM (see Table 2). The TRMM program has three different algorithm products: one based on the passive microwave instrument, the TMI; one based on the radar, the PR; and one based on a combination of the two instruments. The three estimates have been combined into a TRMM composite climatology (TCC) (Adler et al. 2009; Wang et al. 2014), where the local spread among the estimates provides a measure of confidence in the result. As indicated by the spread of estimates in some locations (and the maps in the referenced articles), there can be significant differences between these three estimates in certain regions, but over the large area of the tropical oceans, they are within a few percent of each other, as seen in Table 2. A separate study (Behrangi et al. 2014) used the TRMM PR data and the CloudSat radar and obtained an independent estimate from that of the TCC and the separate TRMM instrument estimates. Again, that TRMM/CloudSat estimate is very close to, but slightly higher than, the GPCP number in the tropics.

TRMM covered only the tropics up to latitude $35^{\circ}$. But what is the result for the middle and higher latitudes over the ocean? Here GPCP is dependent on a mixture of passive microwave-based estimates and empirical relations between cloud and moisture information from satellite sounders and from gauge information, with the influence of the microwave-based estimates decreasing poleward from $40^{\circ}$. Behrangi et al. (2014) also made an estimate from $60^{\circ} \mathrm{N}$ to $60^{\circ} \mathrm{S}$ over ocean using the TRMM and CloudSat radars in the tropics and a combination of passive microwave data from the advanced microwave scanning radiometer (AMSR) on the AQUA satellite and the CloudSat radar in middle and high latitudes. Table 3 indicates that this new estimate of total ocean precipitation is about the same as GPCP (V2.3) for the same years, but slightly higher by about 3\% compared to the earlier V2.2 number. This 3\% difference is within the error bars (Adler et al. 2012) of GPCP, but is also of the same sign (and rough magnitude) of the adjustment needed for water cycle closure (Rodell et al. 2015). Thus, for the same time period the new V2.3 numbers seem to compare very well with the Behrangi et al. (2014) satellite estimates and the Rodell et al. (2015) water balance values. Another merged data analysis product, the Climate Prediction Center Merged Analysis of Precipitation (CMAP) (Xie and Arkin 1997) has a very similar global ocean mean value (Behrangi et al. 2014), but with a higher value in the tropics and a much lower value in high latitudes (Adler et al. 2012; Behrangi et al. 2014). These large-scale tropical and high latitude differences in CMAP are related to its

Table 2 Mean oceanic precipitation estimates ( $\mathrm{mm} /$ day) between $35^{\circ} \mathrm{N}$ and $35^{\circ} \mathrm{S}$ from various products

\begin{tabular}{lllll}
\hline $\begin{array}{l}\text { PR } \\
\text { TRMM precipitation } \\
\text { radar }\end{array}$ & $\begin{array}{l}\text { TMI } \\
\text { TRMM microwave } \\
\text { imager }\end{array}$ & $\begin{array}{l}\text { TCC } \\
\text { TRMM composite } \\
\text { climatology }\end{array}$ & $\begin{array}{l}\text { GPCP } \\
(1998-2014)\end{array}$ & PR + CloudSat \\
\hline 2.9 & 2.8 & 2.9 & 2.99 & 3.0 \\
\hline
\end{tabular}

TRMM and GPCP values are for 1998-2014; the CloudSat value is for 2007-2009 and is from Behrangi et al. (2014) 
Table 3 Global oceanic precipitation estimates ( $\mathrm{mm} /$ day)

\begin{tabular}{llll}
\hline & GPCP $(1998-2014)$ & PR/AMSR/CloudSat & Trenberth $(\mathrm{GPCP}+5 \%)$ \\
\hline $60^{\circ} \mathrm{N}-60^{\circ} \mathrm{S}$ & 3.04 & 3.13 & \\
$90^{\circ} \mathrm{N}-90^{\circ} \mathrm{S}$ & 2.90 & & 3.05 \\
\hline
\end{tabular}

The PR/AMSR/CloudSat value is from Behrangi et al. (2014)

use of IR-based rainfall in the tropics and dependence on passive microwave-based estimates known for underestimation at the higher latitudes (Behrangi et al. 2014).

Both the tropical and total ocean precipitation estimates from GPCP are therefore confirmed (within about $\pm 5 \%$ ) by the newer, more sophisticated estimates using TRMM and CloudSat. It should be pointed out that these very large area totals mask some significant regional differences that need closer attention (Behrangi et al. 2014, 2015).

However, these results do not indicate an end to the discussion of mean ocean rainfall; there is still more to be done. Luckily, the Global Precipitation Measurement (GPM) mission has been launched in 2014 and will provide new, more sophisticated data to continue to refine our knowledge of the absolute magnitude of global precipitation once the GPM precipitation products mature and are validated.

\section{Variations in Global Mean Precipitation (1979-2014)}

Precipitation is highly variable, especially when estimated over small areas and/or short time periods. But how does it vary on a very large scale, for example for the whole planet? And since we know the planet's surface temperature has been increasing during the satellite era, how is that affecting total global precipitation. Figure 3 shows anomalies of global (ocean plus land) surface temperature (top panel) and global total precipitation according to GPCP (lower panel) in the black curves with a 3-month running mean. The surface temperature shows a clear trend during the period (at a rate of $0.16 \mathrm{~K} /$ decade), while the global precipitation shows a near-zero trend [actually a small rate of increase of less than $0.01 \mathrm{~mm} /$ day/decade or $1.3 \% / \mathrm{K}$ (Table 4$)]$. Although this precipitation trend number is close to some estimates based on climate models (e.g., Allen and Ingram 2002; Held and Soden 2006; Sun et al. 2007), it is highly sensitive to the length of record used and other factors (see Gu and Adler 2013). We will revisit this temperature/precipitation trend number later. The global surface temperature and precipitation curves in Fig. 3 show significant inter-annual variations. Taking the trend out of the temperature curve still leaves a standard deviation $(\sigma)$ of $0.15 \mathrm{~K}$ around that trend line. Since the overall change in surface temperature for this period is $\sim 0.6 \mathrm{~K}$, the inter-annual variations are about a quarter of the 36 -year change. For precipitation, $\sigma$ is about $.03 \mathrm{~mm} / \mathrm{day}$, roughly $1 \%$ of the mean. Some of the variance in both parameters probably comes from noise in the original data and the analysis techniques; however, because we are averaging over the entire planet with strong efforts at maintaining homogeneity of the records, most of this variation is likely real.

In an attempt to estimate signals in these global mean records, we have previously used the Nino 3.4 Index as an indicator of ENSO and a stratospheric aerosol index as an indicator of volcano impacts (Gu et al. 2007; Gu and Adler 2011). Using a linear regression approach with relevant time lags (Gu and Adler 2011), we have derived the planetary 
(a) Global land+ocean temperature

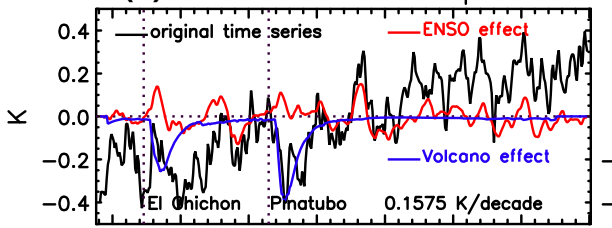

(c) Global land+ocean temperature

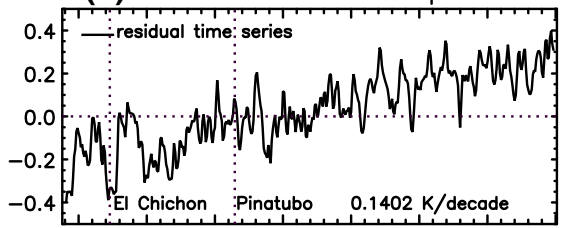

(b) Global land+ocean precipitation

(d) Global land+ocean precipitation
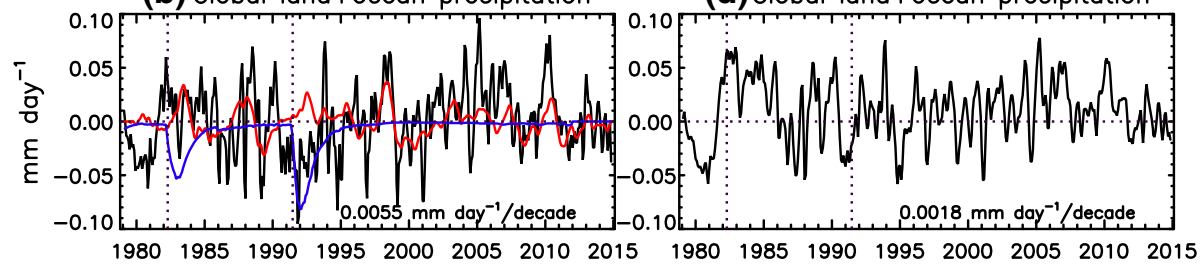

Fig. 3 Time series (January 1979-December 2014) of global mean (land + ocean) surface temperature and precipitation (black lines in the left panel), and corresponding ENSO (red lines) and volcanic effects (blue lines). Time series of residuals (with ENSO and volcanic effects removed) are show in the right panel

Table 4 Linear changes/trends $(\% / \mathrm{K})$ in global precipitation $(P)$ and oceanic columnar water vapor $(\mathrm{CWV})$ with corresponding surface temperature changes (ts)

\begin{tabular}{llll}
\hline & Global land + ocean & Global ocean & Global land \\
\hline$P$ versus ts (1979-2014) & $1.3(0.5)$ & $1.4(0.5)$ & $1.4(-0.4)$ \\
CWV versus ts (1988-2014) & & $9.9(9.8)$ & \\
\hline
\end{tabular}

In parentheses are the respective values with the ENSO and volcano effects removed

surface temperature and precipitation signals related to ENSO and volcanoes (the red and blue lines in Fig. 3).

For ENSO, one can see a global increase in surface temperature (Fig. 3a) for El Ninos (1983, 1988, 1992, 1998, 2010) and negative global anomalies during La Ninas (e.g., 1999-2001). The maximum amplitude occurred during the $1998 \mathrm{El}$ Nino $\left(\sim+0.15^{\circ} \mathrm{C}\right)$, with smaller (negative) amplitudes during La Ninas. For the two major volcanic eruptions during the period, in 1982 (El Chichon) and in 1991 (Pinatubo), there is a sharp drop in surface temperature due to decreased solar radiation at the surface at the time of, and immediately after, the eruptions and then a gradual return to normal mean surface temperature over a 2-3-year period as the volcanic aerosols fell back to Earth. The temperature anomaly magnitude for Pinatubo (the larger event) is $-0.35^{\circ} \mathrm{C}$, a larger magnitude than the $+0.15^{\circ} \mathrm{C}$ estimated global impact of the $1998 \mathrm{El}$ Nino.

Higher surface temperature leads to greater evaporation (especially over ocean) and greater instability; therefore, the inter-annual variations in surface temperature, even if averaged across the globe, tend to be related to variations of the same sign in global precipitation. This is evident in Fig. 3b, where one can easily see increases in global precipitation with El Ninos, decreases with La Ninas and decreases with the two volcanic events [detailed lag-correlation relations can be found in $\mathrm{Gu}$ and Adler (2011)]. The maximum amplitude of the ENSO-related precipitation signal is $+0.04 \mathrm{~mm} /$ day and is made up of a larger increase over oceans and a decrease over land areas (see below). For the two volcanic events, amplitudes of precipitation change of -0.06 and $-0.09 \mathrm{~mm} / \mathrm{day}$ 
are evident. The signs and magnitude of the temperature variations are directly correlated with the amplitude of the precipitation anomalies ( $\mathrm{Gu}$ and Adler 2011). Looking closely one can also identify a lag (precipitation lagging temperature) of $\sim 6$ months for these global signals (Gu and Adler 2011). Past studies have examined the responses of precipitation to temperature variations on the inter-annual time scale using both observations and model outputs (e.g., Adler et al. 2008; Liu and Allan 2012; Liu et al. 2012). Here the precipitation responses are further factored into two mechanisms: ENSO and volcanic eruptions (Table 5). Combining the precipitation and temperature variations for ENSO, a signal of $\sim 9 \% / \mathrm{C}$ is calculated, a little higher, but close to, the Clausius-Clapeyron (C-C) relation of $7 \% / \mathrm{C}$. For the volcano impact, the combined value is $\sim 7.8 \% / \mathrm{C}$. Thus, although the trend signal for precipitation and surface temperature indicates $\sim+0-1.5 \% / \mathrm{C}$, these global variations at the shorter, inter-annual, time scale indicate processes closer to having the Clausius-Clapeyron relation (Table 6).

In Fig. 3c, d, the ENSO and volcano signals are subtracted from the original signal. This reduces the short-term (inter-annual) variability and gives a somewhat better view of the inter-decadal and longer-term signal. During this 1979-to-near-present period, Fig. 3c shows a period of relatively rapid rise in temperature from 1979 to 1998 followed by a shallower slope. With a rough dividing line at about 1998 (middle of the strong El Nino), there seem to be two sub-eras during the satellite era. Overall there is an increase in surface temperature, attributed to $\mathrm{CO}_{2}$-related global warming, with an inter-decadal signal superimposed (e.g., Gu and Adler 2013; Gu et al. 2016). The period after 1998 is sometimes described as the "hiatus" (Trenberth and Fasullo 2013), although recent work may indicate a stronger upward slope as shown here (Karl et al. 2015). But the indication of a "climate shift" related to an inter-decadal process (Dai et al. 2015) is still strong. The precipitation signal after removal of the estimated ENSO and volcano signals (Fig. 3d) still shows a near-zero trend and significant, but slightly reduced, variability.

Figures 4 and 5 show the same type of plots as Fig. 3, but for ocean and land separately. For ocean (Fig. 4) and land (Fig. 5), the temperature curves show the similar qualitative features for ENSO and volcanoes but, although the temperature departure magnitudes for ENSO events are similar over ocean and land, for volcanoes the decreases in temperature are much larger over land. This may be due to volcanoes being located over land, but also the quicker response of surface temperature over land to decreases in solar radiation. The "shift" at 1998 is also evident in both residual time series of surface temperature, although at the end of the time period, the ocean and land seem to show an increase. Could this signal the end of the "hiatus" and a return to a more-rapid warming, being driven from the ocean? For the ocean figure, total column water has been added since 1988 (beginning of SSMI observations). It also shows perturbations related to ENSO and the one volcano

Table 5 Precipitation anomalies related to ENSO and volcanic eruptions versus corresponding surface temperature anomalies over global land, ocean and land + ocean

\begin{tabular}{|c|c|c|c|c|}
\hline & \multicolumn{2}{|l|}{ ENSO effect } & \multicolumn{2}{|l|}{ Volcanic effect } \\
\hline & $\begin{array}{l}\text { Regression coefficient } \\
\left(\mathrm{mm} \mathrm{day}{ }^{-1} / \mathrm{K}\right)\end{array}$ & $\begin{array}{l}\text { Percentage } \\
\text { change }(\% / \mathrm{K})\end{array}$ & $\begin{array}{l}\text { Regression coefficient } \\
\left(\mathrm{mm} \mathrm{day}{ }^{-1} / \mathrm{K}\right)\end{array}$ & $\begin{array}{l}\text { Percentage } \\
\text { change }(\% / \mathrm{K})\end{array}$ \\
\hline Global land & -0.667 & -29.8 & 0.114 & 5.1 \\
\hline Global ocean & 0.555 & 19.2 & 0.311 & 10.8 \\
\hline $\begin{array}{l}\text { Global } \\
\text { land }+ \text { ocean }\end{array}$ & 0.242 & 9.0 & 0.209 & 7.8 \\
\hline
\end{tabular}


Table 6 Oceanic columnar water vapor anomalies related to ENSO and volcanic eruptions versus corresponding surface temperature anomalies

\begin{tabular}{lllll}
\hline ENSO effect & & & Volcanic effect \\
\cline { 1 - 1 } $\begin{array}{llll}\text { Regression coefficient } \\
(\mathrm{mm} / \mathrm{K})\end{array}$ & $\begin{array}{l}\text { Percentage change } \\
(\% / \mathrm{K})\end{array}$ & & $\begin{array}{l}\text { Regression coefficient } \\
(\mathrm{mm} / \mathrm{K})\end{array}$ & $\begin{array}{l}\text { Percentage change } \\
(\% / \mathrm{K})\end{array}$ \\
\hline 4.31 & 15.2 & 2.52 & 8.9 \\
\hline
\end{tabular}

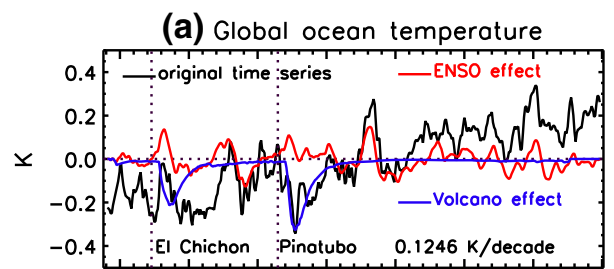

(b) Global ocean CWV

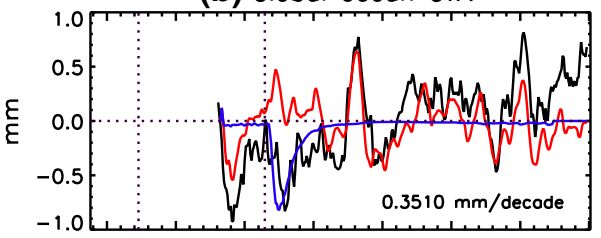

(c) Global ocean precipitation

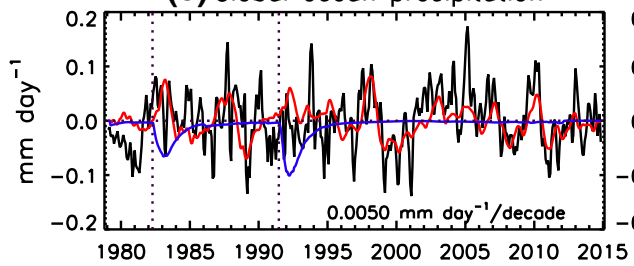

(d) Global ocean temperature

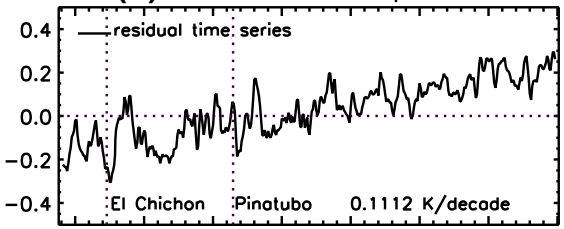

(e) Global ocean CWV

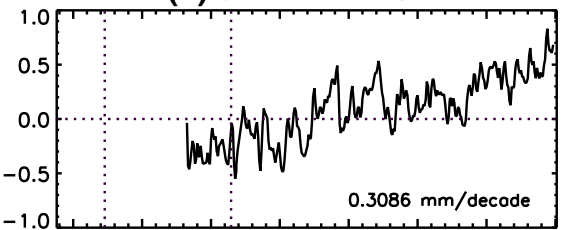

(f) Global ocean precipitation

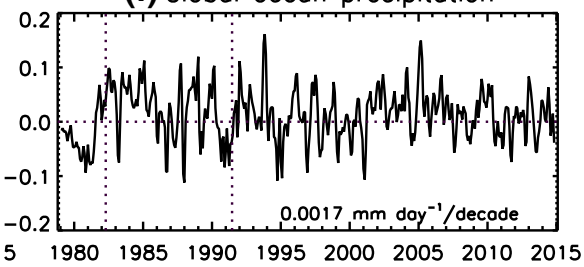

Fig. 4 Time series (January 1979-December 2014) of global mean SST anomalies, oceanic columnar water vapor $(\mathrm{CWV})$, and oceanic precipitation (black lines in the left panel), and corresponding ENSO (red lines) and volcanic effects (blue lines). Time series of residuals (with ENSO and volcanic effects removed) are show in the right panel

during the period in the same directions as the surface temperature. The residual curve for water vapor indicates the leveling off after 1998, but an increase starting around 2008, perhaps in relation to changes in the sea surface temperature (SST) residual curve. It is also noted that, different from a small increased rate for global ocean precipitation, oceanic water vapor has a much larger increase rate (Table 4), generally consistent with the results of Wang et al. (2016).

For precipitation, the ocean and land plots show the expected opposite sign anomalies for ENSO. For an El Nino (e.g., 1998), the precipitation anomaly over ocean is positive and over land is negative. This is, of course, due to the pattern of rainfall anomalies, mainly over the tropics, with a large positive anomaly over the central/eastern Pacific Ocean and the largest negative anomalies over the Maritime Continent and the Amazon. The opposite effect is present for La Nina. Thus, the global total (land plus ocean) precipitation 
(a) Global land temperature

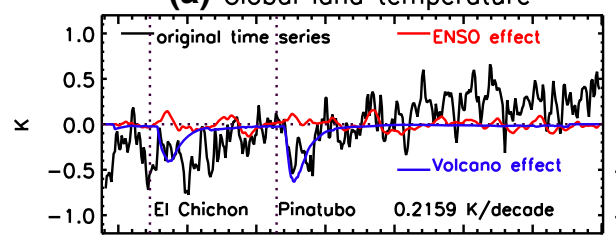

(b) Global land precipitation

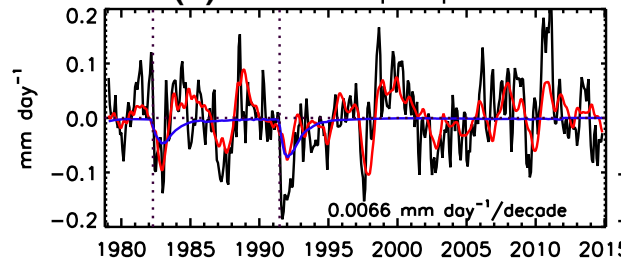

(c) Global land temperature

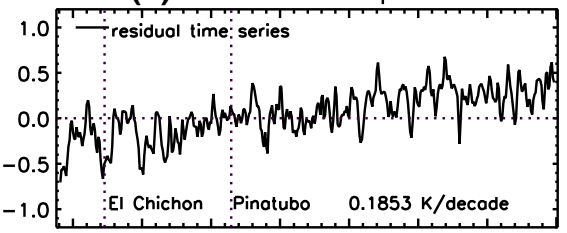

(d) Globol land precipitation

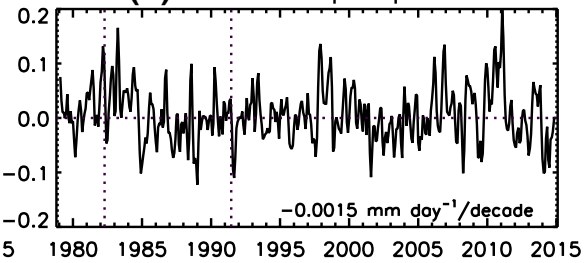

Fig. 5 Time series (January 1979-December 2014) of global mean land surface temperature and precipitation (black lines in the left panel), and corresponding ENSO (red lines) and volcanic effects (blue lines). Time series of residuals (with ENSO and volcanic effects removed) are shown in the right panel

anomalies for ENSO are a difference between the ocean and land values, with the land and ocean magnitudes being about the same (in terms of $\mathrm{mm} /$ day), but the sign of the ocean changes winning out due to the much larger area. In contrast for the volcanic eruptions, the magnitude of negative departure is about the same over land and ocean. The residual plots for precipitation both indicate a lack of trend, although the land curve shows a negative departure during the last few years. This may relate to not having the full gauge precipitation data set used for the earlier years, since it takes a few years for the full complement of precipitation data to be available for analysis.

With these characteristics of changes well defined on the planetary scale for the satellite era, we have a large-scale definition of variations that should be replicated by climate models as research moves forward. Even though free-running climate models will not reproduce the specific events of the satellite era as described in Figs. 3 and 4, the statistics of the model ENSO events, e.g., temperature and precipitation amplitudes, can be compared to these observation-based estimates. For climate models covering the satellite era that are forced by SST and aerosol observations (AMIP-type simulations), we can get closer to validating the model-generated specific events.

\section{Patterns of Precipitation Variation}

In the last section, one could see that, even when precipitation was averaged across the entire planet, we could pick out variations on inter-annual and inter-decadal timescales and show that phenomena such as ENSO and volcanoes could be detected on a planetary scale. We also saw that while surface temperature has increased significantly during the satellite era, the calculated trend in mean precipitation from the GPCP data set is near zero. In this section, we look at regional changes, including inter-annual and inter-decadal changes, and trends during this relatively short period.

Patterns of precipitation anomalies have been the subject of numerous studies (e.g., Dai and Wigley 2000; Held and Soden 2006; Xie et al. 2010; Gu and Adler 2013). However, with global estimates from GPCP we can summarize the mean impact of ENSO during the 
satellite era across the globe. Figure 6 shows the summary of ENSO anomalies. It is constructed by splitting the Nino 3.4 index based on SST anomalies in the central Pacific into three categories: An El Nino is defined when the index is in the highest one-third months of the index, and La Nina is defined when the index is in the lowest one-third of the distribution. The middle third is defined as neutral. Figure 6 is the result of taking the mean anomalies of the El Nino months and subtracting the mean anomalies of the La Nina months. Since the La Nina patterns tend to be a mirror image of El Nino pattern, they tend to reinforce each other.

The result in Fig. 6 shows a dramatic, alternating pattern of large positive and negative anomalies along the equator, with the largest (over $5 \mathrm{~mm} /$ day) positive peak in the central Pacific, associated with the typical maximum (with El Nino) surface temperature anomaly. The largest negative (weaker) anomaly is over the Maritime Continent to the west. The positive anomaly stretches eastward from its core right up to the coast of South America, where there is a marked shift to a deficit of rainfall over Amazonia. There is also a weaker positive anomaly over the western Indian Ocean, but these equatorial features weaken as they approach the opposite longitude of the primary maximum at about $180^{\circ}$ longitude. Moving off the equator into the southern hemisphere, there are strong extensions of the equatorial features oriented northwest to southeast. The negative anomaly over the Maritime Continent can be seen extending across a long swath of the south Pacific Ocean to the area between Tierra del Fuego and Antarctica at $60^{\circ} \mathrm{S}$. From the central Pacific positive anomaly, one can faintly trace a feature across southern South America, into the South Atlantic and below the tip of Africa. The positive anomaly over East Africa and the Equatorial Indian Ocean also extends southeastward. The Amazon feature extends across the Equatorial Atlantic into Africa.

In the northern hemisphere, the features are more fragmented, probably due to the impact of the larger continents and associated mountain ranges, especially in Asia. However, the extensive positive feature across the subtropical eastern Pacific into the southern USA and beyond all the way to western Europe seems to be linked to the original, largest positive anomaly on the equator at the Dateline. This map and the features therein are composites of a number of both El Ninos and La Ninas. Each individual event is different, but the fact that the composites have features that cover vast areas at their core and extend across oceans and continents indicates the impact of ENSO on the geographic distribution of precipitation.

The effects of the two distinct ENSO flavors (warm SST anomalies centered in central or eastern Pacific; e.g., Ashok et al. 2007) on precipitation are examined as well by a composite analysis (Fig. 7). Four individual winter seasons are chosen for the eastern (EP)

Fig. 6 Composite precipitation anomaly differences ( $\mathrm{mm} /$ day) between ENSO warm (defined as Nino $3.4 \geq 0.35$ ) and cold phases (Nino $3.4 \leq-0.45$ ). The number of months for either phase is 143 (one-third of months) during 1979-2014
GPCP (Nino 3.4)

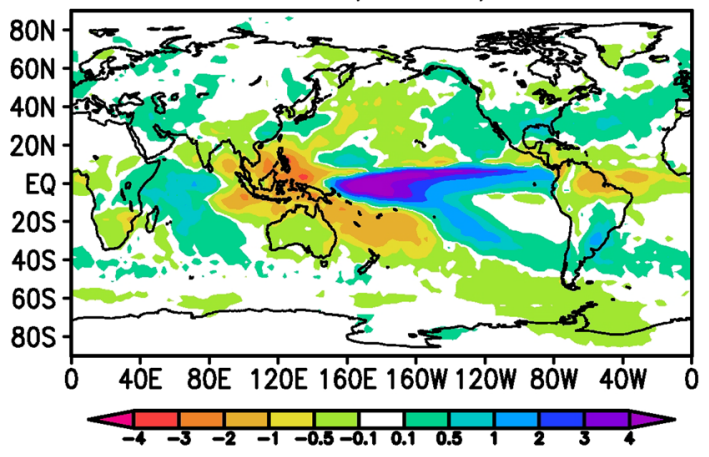


and central $(\mathrm{CP})$ Pacific events based on the seasonal mean values of the respective indices derived from an empirical orthogonal function (EOF) analysis of monthly SST anomalies between $30^{\circ} \mathrm{N}$ and $30^{\circ} \mathrm{S}$ ( $\mathrm{Gu}$ and Adler 2016). The years chosen for composites are generally consistent with those of Yu et al. (2012). Spatial features of EP-related precipitation anomalies are in agreement with the conventional, canonical ENSO events (e.g., Dai and Wigley 2000; Curtis and Adler 2003) and are in agreement with Fig. 6. However, precipitation anomalies associated with $\mathrm{CP}$ events are relatively weak and the zone of maximum positive anomalies shifts farther west (near about $140^{\circ} \mathrm{E}$ ) covering a large portion of tropical western Pacific (Fig. 7b). East of the Dateline, a band of negative anomalies occupies the equatorial region with a narrow band of positive anomalies north of it, indicating a northward shift of the climatological inter-tropical convergence zone (ITCZ) (e.g., Ashok et al. 2007), in contrast to the southward shift of the ITCZ associated with EP events (Fig. 7a). In the Indian Ocean and Atlantic, different spatial features can also be readily seen between these two ENSO flavors. Additional analysis of impacts of these variations of ENSO on precipitation is discussed in Gu and Adler (2016).

Variations of regional precipitation due to ENSO are significant, but since they are associated with an inter-annual phenomenon, these variations do not significantly affect long-term regional changes. As well, although the global mean precipitation (and even that averaged over land and ocean separately) has a near-zero trend, that does not mean that regional trends are zero, and they are not. Figure 8 shows the regional trends of surface temperature, total column water vapor (over the ocean) and precipitation during the satellite era. Immediately obvious is that even the surface temperature trend pattern is not uniform (e.g., Hansen et al. 1999). While the global trend number is $+0.1{ }^{\circ} \mathrm{C} / \mathrm{dec}$ ade for the period in question, there is significant spatial variability across the globe, varying from about $+0.5{ }^{\circ} \mathrm{C} /$ decade in the north polar regions to about $-0.2{ }^{\circ} \mathrm{C} /$ decade in the eastern Pacific and across the southern ocean at high latitudes. The sea surface temperature (SST) trend pattern in the Pacific during this recent era is different from that of a longer period back through the twentieth century, which shows a more uniform warming over the ocean, although still with some variations. These differences highlight the fact that our satellite era is still a relatively short period (36 years) for characterizing climate trends and that factors at the inter-decadal time scale could play an important role in shaping the pattern of trends for the satellite era.

The oceanic water vapor trend pattern (Fig. 8b) shows a pattern very similar to the SST change pattern, with the largest water vapor increases linked to the maxima in increases in

(a) GPCP (Eastern EI Nino)

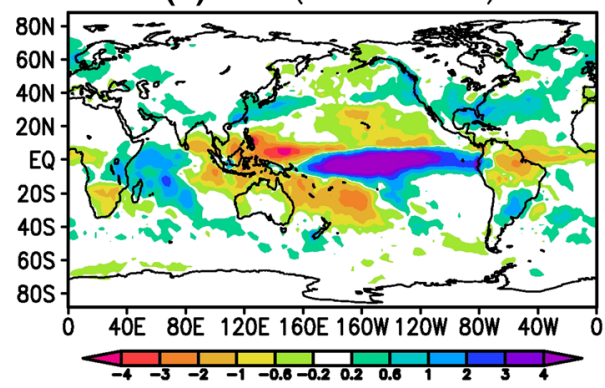

(b) GPCP (Central El Nino)

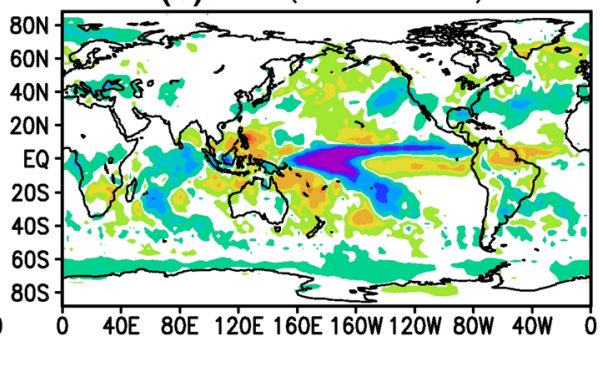

Fig. 7 Composite precipitation anomalies during boreal winter (Dec-Jan-Feb-Mar) for the (a) eastern and b central Pacific El Niño events. The years for compositing are 1982/1983, 1986/1987, 1997/1998, and $2006 / 2007$ for the eastern events, and 1994/1995, 2002/2003, 2004/2005, and 2009/2010 for the central events 
(a) ts $(1979-2014)$

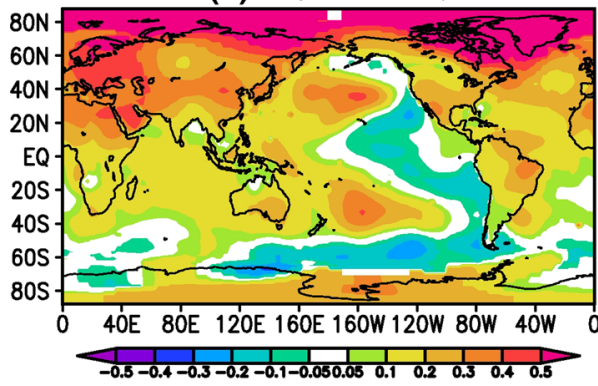

(c) $P(1979-2014)$

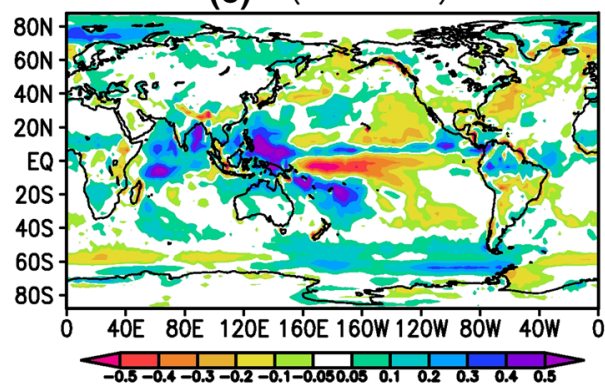

(b) CWV (1988-2014)

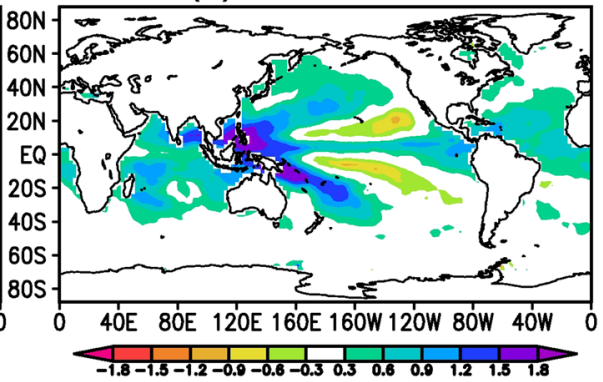

Fig. 8 Long-term trends in surface temperature, columnar water vapor, and precipitation (1979-2014 for $t_{\mathrm{s}}$ and $P, 1988-2014$ for CWV)

surface temperature in the tropical western Pacific, Indian and Atlantic Oceans. A significant difference is the water vapor increase along the ITCZ across the Pacific, with areas of decreases north and south of the ITCZ. These water vapor trends over the ocean are related to increased evaporation associated with increased surface temperature, but also to moisture transport, including transport into the ITCZ.

The precipitation trend pattern (Fig. 8c) is noisier than either the surface temperature or water vapor pattern, but resembles the water vapor pattern over the tropical oceans. For example, it shows a very narrow feature of increase along the ITCZ in the Pacific, the western Pacific area of increase, along with the increase in the South Pacific convergence zone (SPCZ), and increases in the tropical Indian and Atlantic Oceans. Decreases are noted on either side of the Pacific ITCZ, again nearly co-located with the water vapor change. Positive-change extensions toward mid-latitudes are seen emanating from the western Pacific maximum aligned approximately with the water vapor and SST positive-change areas. There is also an area of positive change at $60^{\circ} \mathrm{S}$ in the southern Pacific. Over land, there is positive/negative pattern of change over South America going from north to south, a weak pattern over Africa and a general area of increase over land along $60^{\circ} \mathrm{N}$, especially evident over Asia. Across North America, there is weak negative change across the southwest USA and Mexico and extending to the east coast. Weak increases are indicated from Alaska, across Canada and the Great Lakes to the east.

The pattern of precipitation trend in Fig. $8 \mathrm{c}$ is related to the patterns of trend in surface temperature and ocean water vapor in a complicated way, integrating processes from the weather scale through inter-annual and inter-decadal changes up through the impact of global warming. The result of these processes can be seen in some of the pattern relations 
in the figures, but are difficult to separate. Figure 8c is arguably the best, globally complete, observation-based estimate of precipitation trend over this long a period (36 years).

Since this period is concurrent with a period of significant global warming, one key question is whether the observed pattern is largely the result of that planetary warming? Having such an observed pattern in which we have confidence would be useful for understanding the recent past, for assuming a similar future pattern of change and for comparison and validation with climate models of global warming covering the past and projecting future precipitation patterns. While short-term processes up through inter-annual presumably average out, the relatively short period of the satellite era could allow effects of inter-decadal processes to be evident. Indeed, that appeared to be the case on the planetary scale when examining the global surface temperature and water vapor trends in the previous section.

Figure 9 shows the time history during the satellite era of three SST-based indices of climate scale variations. In the top panel is the Nino 3.4 index related to ENSO, where high positive values are related to El Ninos. In the middle panel is the Pacific Decadal Oscillation (PDO) index, a gradient of SST in the northern Pacific, and the bottom panel shows the Atlantic Multi-decadal Oscillation (AMO) index. While the Nino 3.4 index shows no obvious inter-decadal changes, the PDO and AMO show a shift around 1998. Although the global precipitation plot (Fig. 3b) does not show the "shift" around 1998, the inter-decadal change signal could be affecting the pattern of the precipitation trend. Recent work (Gu and Adler 2013; Gu et al. 2016) attacked this problem to separate the signal associated with possible inter-decadal processes and isolate the global warming (GW) signal as much as possible. Here we present updated results of these studies with additional years and the new version of the GPCP data set.

The technique used to separate the signals is described in detail in $\mathrm{Gu}$ et al. (2016), which is in general similar to the method used in Thompson et al. (2000). It basically uses the two indices representing PDO and AMO as predictors to estimate the regression coefficients between these two mechanisms and precipitation variations. Their contributions to the total precipitation changes/trends can then be estimated by multiplying the corresponding regression coefficients with the linear trend in the two indices. Furthermore, the effects of other mechanisms such as anthropogenic greenhouse gases (GHG) and aerosols are estimated by subtracting the PDO and AMO contributions from the total trends. As discussed in Gu et al. (2016), the effects from aerosols and natural forcings on the trends tend to be opposite and are much weaker than the anthropogenic GHG impact that dominates the residuals.

The result is summarized in Fig. 10. The upper-left panel (Fig. 10a) is a repeat of the observed precipitation trend pattern. Figure $10 \mathrm{~b}$ shows the trend pattern related to the PDO change during the era, with a focus in the Pacific and showing some similarity to the observed pattern (Fig. 10a) in that region. The AMO-related change pattern (Fig. 10c) shows a wider geographic spread to the features, with somewhat opposite sign signals from the PDO in the Pacific, and features similar to the observed in the Atlantic and Indian Oceans. Although these estimates of PDO- and AMO-related trends are likely not exact, they give an estimate of how these inter-decadal signals affect the change during this relatively short period. Subtracting these effects from the observed pattern gives an estimate of the change pattern due to remaining processes (Fig. 10d), in this case global warming. Although all these processes are intertwined, this linear removal process based on the change in the indices hopefully gives a better estimate of the GWrelated trend than just the change in the observations themselves. The estimated GWrelated pattern in Fig. 10d has a stronger positive trend area along the Pacific ITCZ and 
(a) Nino 3.4

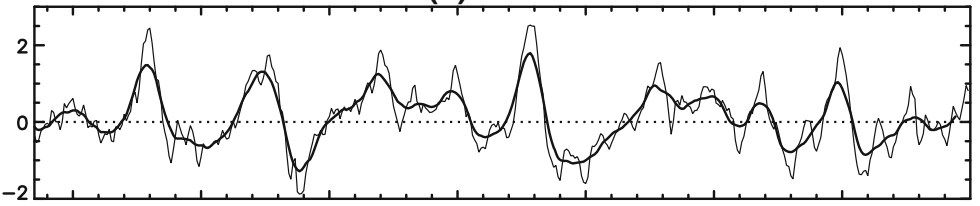

(b) PDO

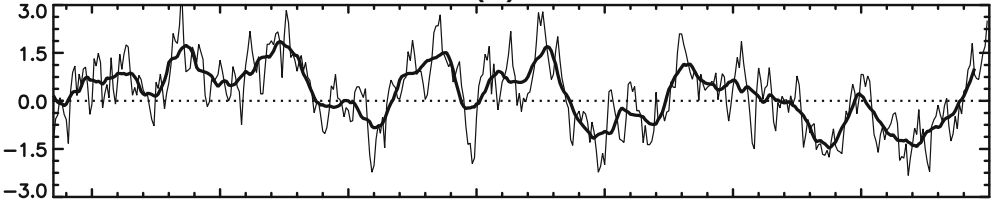

(c) AMO

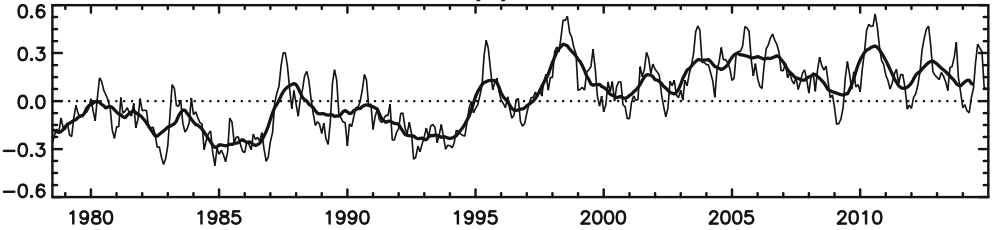

Fig. 9 Time series of monthly a Nino 3.4, b PDO and c AMO indices (thin lines). Also shown are the corresponding 13-monthly running means (thick lines) during 1979-2014. Nino 3.4 is used to represent the ENSO events, estimated from SST anomalies averaged over a domain of $5^{\circ} \mathrm{N}-5^{\circ} \mathrm{S}, 120-170^{\circ} \mathrm{W}$ in the tropical Pacific to represent the ENSO. The PDO index was downloaded from the University of Washington (http://jisao.washington.edu/pdo/PDO.latest), and the AMO index was downloaded from NOAA/ERSL/PSD (http://www.esrl.noaa.gov/psd/data/timeseries/AMO/)

(a) GPCP (trend)

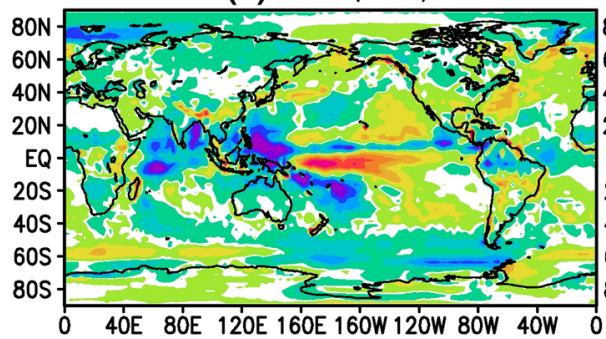

(c) GPCP (trend; AMO)

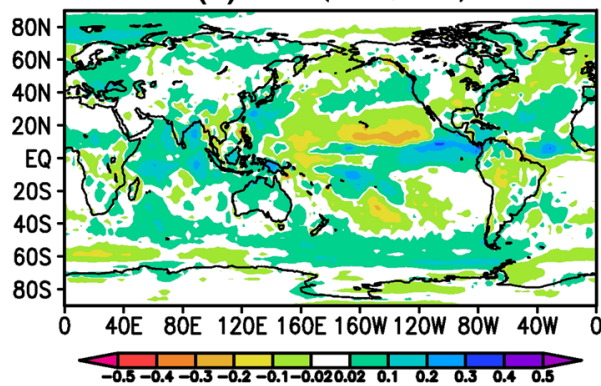

(b) GPCP (trend; PDO)

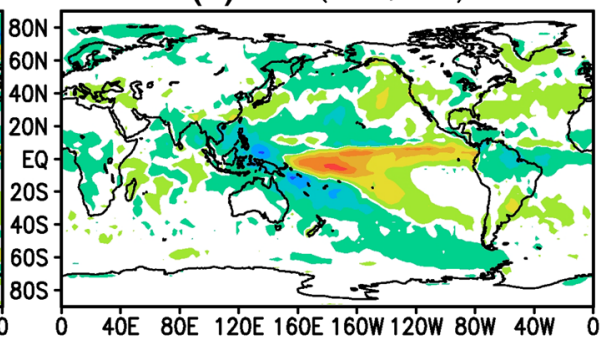

(d) GPCP (trend; No PDO or AMO)

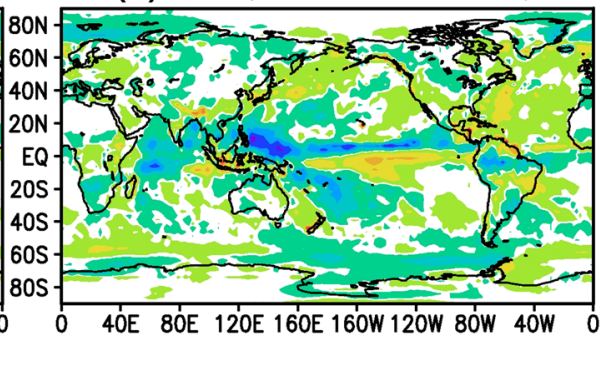

Fig. 10 a Linear trends of GPCP precipitation (mm/day per decade) during 1979-2014. b Linear trends associated with PDO. c Linear trends associated with AMO. d Linear tends with no PDO or AMO effect 
weaker negative areas north and south of the ITCZ. Although the positive maxima over the western Pacific, SPCZ and Indian Ocean are still there, they are somewhat weaker. Similar differences can be found over oceans at higher latitudes. Over land, features are still similar, but weaker. A case can be made that this overall trend pattern matches better with that derived from climate models for the same period using $\mathrm{GW}$ forcing ( $\mathrm{Gu}$ et al. 2016).

Looking at the trend distribution from a zonally averaged standpoint helps to give a more planetary-scale view. Figure 11 shows the latitudinal distribution of trends in surface temperature and precipitation during the period in question. In the top panels (Figs. 11a and b), the temperature trend shows almost all latitudes having an increase, with the largest values at high northern latitudes. The decomposition of this temperature trend profile leaves the residual (the estimated GW portion) with the same shape, but with a reduced peak value in the north. On the precipitation side (Fig. 11c, d), the observed precipitation trend (black curve, Fig. 11c) shows a sharp peak just north of the Equator and a negative feature just south of that. The positive trend peak is co-located with the maximum mean precipitation (red curve) along the ITCZ. In the northern hemisphere, the trend shows a negative sign in mid-latitudes and then a secondary peak at higher latitudes. In the southern hemisphere, the trend is very variable. When the precipitation trend is decomposed, the residual or GW signal is similar to the observed (the black lines in Fig. 11d, c, respectively), but with smaller and less variable features.
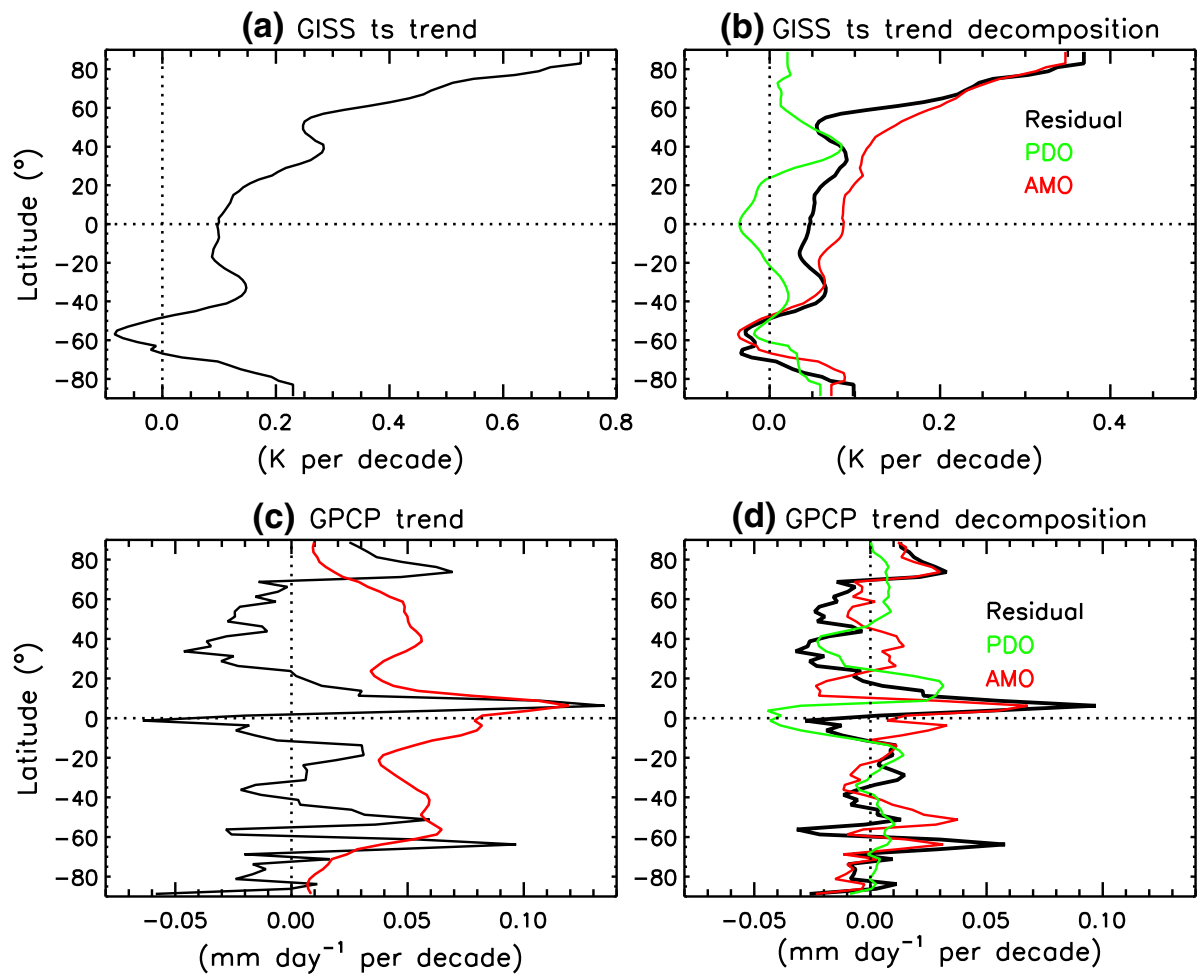

Fig. 11 Zonal mean temperature and precipitation trends and decompositions during 1979-2014. Also shown in (c) is the zonal mean profile of climatological mean precipitation (red curve; scaled by 50 with resulting units of $\mathrm{mm} /$ day) 


\section{Summary}

Satellite observations over the last 36 or so years have allowed for a much more accurate estimation of precipitation over the entire globe. This satellite era has also allowed for a close study of variations and trends during this period to better understand the regional and global changes in this particularly important variable. The current GPCP climatological map shows the well-known precipitation features of both the tropics and the middle and high latitudes, but now gives what might be termed as mature estimates of mean values of these regional features. In terms of mean annual precipitation over the entire globe, the GPCP number is $2.69 \mathrm{~mm} /$ day with an estimated error of approximately $\pm 7 \%$. The ocean and land totals when separated are 2.89 and $2.24 \mathrm{~mm} /$ day, respectively. The global number (and the ocean and land components) fits reasonably into large-scale water budgets using estimates of other branches of the water cycle (e.g., evaporation, transport), with perhaps an indication of a small underestimation over ocean. A similar value of possible underestimation over global oceans is obtained from examination of newer satellite-based estimates over a shorter period. Although there may be some "missed precipitation" on the light end of the intensity spectrum, the likely source of most of any underestimation probably comes from the underestimation of events or periods of heavy rainfall over tropical oceans. These absolute magnitudes will be refined as further analyses are done using data from the Global Precipitation Measurement (GPM) mission and other new measurements and careful comparisons with ground measurements.

During the satellite era, the global surface temperature has increased, although not at a constant rate, and atmospheric water vapor has also increased. However, the global precipitation value has shown no significant positive trend over the period. Variations of precipitation are evident on even the largest scale, for the entire globe, and the separate ocean and land areas. ENSO, even though focused in the tropical Pacific Ocean, affects the global mean surface temperature, water vapor and precipitation magnitudes. During El Ninos, global values of all three variables increase. For surface temperature, increases up to $0.15{ }^{\circ} \mathrm{C}$ are noted, with a corresponding increase of $0.4 \mathrm{~mm} /$ day for global precipitation, making for a rate of precipitation increase of $9 \% / \mathrm{C}$, near the Clausius-Clapeyron rate. La Nina events produce a smaller, negative temperature and precipitation signal for global temperature and precipitation. The two volcanic events during the period also produce temperature, water vapor and precipitation signals, all with a negative sign, up to $0.09 \mathrm{~mm} /$ day or around a $3 \%$ dip in global precipitation. Along with a same sign change in temperature, this also gives a precipitation-temperature rate change of near the $\mathrm{C}-\mathrm{C}$ value $(8 \% / \mathrm{C})$. These values associated with the inter-annual processes related to ENSO and volcanoes that are roughly equal to the $\mathrm{C}-\mathrm{C}$ values differ from the long-term or trend process that shows a roughly zero trend. Thus, there is a significant difference between how processes affect these relations on the inter-annual versus the trend scales.

In addition to affecting global precipitation, ENSO events show a very strong signal in the patterns of precipitation anomalies across the tropics and into middle and high latitudes. Utilizing the 36-year period allows for multiple ENSO events to determine a mean or composite impact. The results show the alternating areas of positive and negative rainfall anomalies along the equator stretching east and west from the largest anomaly in the central Pacific and becoming weaker toward the west in Africa and toward the east in the Atlantic. But also obvious are extensions from the tropical features into middle and even high latitudes, indicating the extensive impact of this phenomenon. 
Although the global total precipitation shows no significant trend, the pattern or map of observed trends shows a very distinctive pattern of positive and negative precipitation changes, with some linkages to the trend patterns for surface temperature and water vapor. Increasing rainfall is dominant in the western Pacific and Indian Ocean, in a narrow belt along the ITCZ location in the central and eastern Pacific and in the SPCZ. Areas of reduction are noted on either side of the ITCZ extending into the eastern Pacific and onto land (e.g., across the southern U.S.).

Since there has been significant overall warming of the planet during this time period, a question arises if this observed pattern is the pattern of precipitation change due to global warming. Can we use this pattern as an indicator of future changes? However, because the satellite era is relatively short in terms of climate change, the impact of an inter-decadal precipitation change signal is examined to eliminate the effect of a PDO- and AMO-based shift around 1998-2000. The resulting pattern of change signal strengthens the ITCZlocated increase in precipitation across the Pacific and shifts and moderates some other features and gives a closer pattern from that estimated from climate models running a GW scenario. This pattern is also similar to that estimated using various observations, reconstructions and models for the much longer period of the twentieth century ( $\mathrm{Gu}$ and Adler 2015).

All these results indicate the utility of the GPCP analyses and the value of this type of globally complete composite analysis of observations, including satellite and ground information. There is still much to be done in terms of utilizing new data sets and integrating them into the analysis without causing significant inhomogeneities to the analysis record. These new estimates, for example from TRMM, CloudSat and GPM, will help in many ways to improve the analyses and allow for some adjustment of earlier periods. Areas of needed research emphasis include intense tropical rainfall where even the TRMM and GPM radars reach saturation, and light precipitation over both land and ocean, especially in middle and high latitudes. With this satellite era record extending, as time moves on its usefulness for comparison with models and in interpreting variations in terms of longer changes such as at the inter-decadal and trend scales will improve. However, the long-term record necessarily uses different satellites with different instruments of varying capabilities. Piecing these records together in time and in space (e.g., tropical and high latitudes) may require an increased focus on GPCP-type analyses. Methods to extend the analysis back in time before the satellite era will be limited, of course, by the lack of sufficient direct ocean estimates, but can be used with over-land gauge estimates and both numerical and statistical models. There is no doubt that a better understanding of all these scales of variations of precipitation on our planet will require continued extension and improvement in global precipitation analyses.

Open Access This article is distributed under the terms of the Creative Commons Attribution 4.0 International License (http://creativecommons.org/licenses/by/4.0/), which permits unrestricted use, distribution, and reproduction in any medium, provided you give appropriate credit to the original author(s) and the source, provide a link to the Creative Commons license, and indicate if changes were made.

\section{References}

Adler RF, Huffman GJ, Chang A, Ferraro R, Xie P, Janowiak J, Rudolf B, Schneider U, Curtis S, Bolvin D, Gruber A, Susskind J, Arkin P, Nelkin E (2003) The version 2 Global Precipitation Climatology Project (GPCP) monthly precipitation analysis (1979-present). J Hydrometeorol 4:1147-1167 
Adler RF, Gu G, Wang J-J, Huffman GJ, Curtis S, Bolvin D (2008) Relationships between global precipitation and surface temperature on interannual and longer timescales (1979-2006). J Geophys Res 113:D22104. doi:10.1029/2008JD10536

Adler RF, Wang J-J, Gu G, Huffman GJ (2009) A ten-year tropical rainfall climatology based on a composite of TRMM products. J Meteorol Soc Jpn 87A:281-293

Adler RF, Gu G, Huffman G (2012) Estimating climatological bias errors for the Global Precipitation Climatology Project (GPCP). J Appl Meteorol Climatol 51:84-99

Allen MR, Ingram WJ (2002) Constraints on future changes in climate and the hydrologic cycle. Nature 419:224-232

Arkin PA, Xie P (1994) The global precipitation climatology project: first algorithm intercomparison project. Bull Am Meteorol Soc 75:401-419

Ashok K, Behera SK, Rao SA, Weng H, Yamagata T (2007) El Niño Modoki and its possible teleconnection. J Geophys Res 112:C11007. doi:10.1029/2006JC003798

Behrangi A, Stephens G, Adler RF, Huffman GJ, Lambrigtsen B, Lebsock M (2014) An update on the oceanic precipitation rate and its zonal distribution in light of advanced observations from space. J Clim 27:3957-3965. doi:10.1175/JCLI-D-13-00679.1

Behrangi A, Nguyen H, Lambrigtsen B, Schreier M, Dang V (2015) Investigating the role of multi-spectral and near surface temperature and humidity data to improve precipitation detection at high latitudes. Atmos Res 163:2-12. doi:10.1061/j.atmospheres.2014.10.019

Curtis S, Adler RF (2003) Evolution of El Niño-precipitation relationships from satellites and gauges. J Geophys Res 108(D4):4153. doi:10.1029/2002JD002690

Dai A, Wigley TML (2000) Global patterns of ENSO-induced precipitation. Geophys Res Lett 27:1283-1286

Dai A, Fyfe JC, Xie S-P, Dai X (2015) Decadal modulation of global surface temperature by internal climate variability. Nat Clim Chang 5:555-559. doi:10.1038/nclimate2605

Gu G, Adler RF (2011) Precipitation and temperature variations on the interannual time scale: assessing the impact of ENSO and volcanic eruptions. J Clim 24:2258-2270

Gu G, Adler RF (2013) Interdecadal variability/long-term changes in global precipitation patterns during the past three decades: global warming and/or Pacific decadal variability? Clim Dyn 40:3009-3022. doi:10.1007/s00382-012-1443-8

Gu G, Adler RF (2015) Spatial patterns of global precipitation change and variability during 1901-2010. J Clim 28:4431-4453. doi:10.1175/JCLI-D-14-00201.1

Gu G, Adler R (2016) Precipitation, temperature, and moisture transport variations associated with two distinct ENSO flavors during 1979-2014. Clim Dyn. doi:10.1007/s00382-016-3462-3

Gu G, Adler RF, Huffman GJ, Curtis S (2007) Tropical rainfall variability on interannual-to-interdecadal/longer-time scales derived from the GPCP monthly product. J Clim 20:4033-4046

Gu G, Adler RF, Huffman GJ (2016) Long-term changes/trends in surface temperature and precipitation during the satellite era (1979-2012). Clim Dyn 46:1091-1105. doi:10.1007/s00382-015-2634-X

Hansen J, Ruedy R, Glascoe J, Sato M (1999) GISS analysis of surface temperature change. J Geophys Res 104:30997-31022

Held IM, Soden BJ (2006) Robust responses of the hydrological cycle to global warming. J Clim 19:5686-5699

Hou AY, Kakar R, Neeck S, Azarbarzin A, Kummerow C, Kojima M, Oki R, Nakamura K, Iguchi T (2014) The global precipitation measurement (GPM) mission. Bull Am Meteorol Soc. doi:10.1175/BAMS-D13-00164.1

Huang B et al (2015) Extended reconstructed sea surface temperature version 4 (ERSST.v4). Part I: upgrades and intercomparisons. J Clim 28:911-930. doi:10.1175/JCLI-D-14-00006.1

Huffman GJ, Adler RF, Bolvin DT, Gu G, Nelkin EJ, Bowman K, Hong Y, Stocker EF, Wolff D (2007) The TRMM multi-satellite precipitation analysis (TMPA): quasi-global, multi-year, combined-sensor precipitation estimates at fine scales. J Hydrometeorol 8:38-55

Huffman GJ, Adler RF, Bolvin DT, Gu G (2009) Improvements in the GPCP global precipitation record: GPCP Version 2.1. Geophys Res Lett 36:L17808. doi:10.1029/2009GL040000

Jaeger L (1983) Monthly and areal patterns of mean global precipitation. In: Street-Perrott A, Beran M, Ratcliffe R (eds) Variations in the global water budget. Springer, Netherlands, pp 129-140

Karl TR, Arguez A, Huang B, Lawrimore JH, McMahon JR, Menne MJ, Peterson TC, Vose RS, Zhang Huai-Min (2015) Possible artifacts of data bases in the recent global surface warming hiatus. Science 348:1469-1472. doi:10.1126/science.aaa5632

Kummerow C, Simpson J, Thiele O, Barnes W, Chang ATC, Stocker E, Adler RF, Hou A, Kakar R, Wentz F, Ashcroft P, Kozu T, Hong Y, Okamoto K, Iguchi T, Kuroiwa H, Im E, Haddad Z, Huffman G, Ferrier B, Olson WS, Zipser E, Smith EA, Wilheit TT, North G, Krishnamurti T, Nakamura K (2000) 
The status of the tropical rainfall measuring mission (TRMM) after 2 years in orbit. J Appl Meteorol 39(12):1965-1982

L'Ecuyer T, Beaudoing H, Rodell M, Olson W, Lin B, Kato S, Clayson C, Wood E, Sheffield J, Adler R, Huffman G, Bosilovich M, Gu G, Robertson F, Houser P, Chambers D, Famiglietti J, Fetzer E, Liu W, Gao X, Schlosser C, Clark E, Lettenmaier D, Hilburn K (2015) The observed state of the energy budget in the early twenty-first century. J Clim 28:8319-8346. doi:10.1175/JCLI-D-14-00556.1

Liu C, Allan RP (2012) Multisatellite observed response of precipitation and its extremes to interannual climate variability. J Geophys Res 117:D03101. doi:10.1029/2011JD016568

Liu C, Allan RP, Huffman GJ (2012) Co-variation of temperature and precipitation in CMIP5 models and satellite observations. Geophys Res Lett 39:L13803. doi:10.1029/2012GL052093

Rodell M, Beaudoing HK, L'Ecuyer T, Olson W, Famiglietti JS, Houser PR, Adler R, Bosilovich M, Clayson CA, Chambers D, Clark E, Fetzer E, Gao X, Gu G, Hilburn K, Huffman G, Lettenmaier DP, Liu WT, Robertson FR, Schlosser CA, Sheffield J, Wood EF (2015) The observed state of the water cycle in the early 21st century. J Clim 28:8289-8318. doi:10.1175/JCLI-D-14-00555.1

Schneider U, Becker A, Finger P, Meyer-Christoffer A, Ziese M, Rudolf B (2014) GPCC's new land surface precipitation climatology based on quality-controlled in situ data and its role in quantifying the global water cycle. Theor Appl Climatol 115:15-40. doi:10.1007/s00704-013-0860-x

Smith TM, Reynolds RW, Peterson TC, Lawrimore J (2008) Improvements to NOAA's historical merged land-ocean surface temperature analysis (1880-2006). J Clim 21:2283-2296

Stephens GL, Vane DG, Boain RJ, Mace GG, Sassen K, Wang Z, Illingworth AJ, O'Connor EJ, Rossow WB, Durden SL, Miller SD, Austin RT, Benedetti A, Mitrescu C, The CloudSat Science Team (2002) The CloudSat mission and the A-train: a new dimension to space-based observations of clouds and precipitation. Bull Am Meterol Soc 83:1771-1790

Stephens GL, Li JL, Wild M, Clayson CA, Loeb N, Kato S, L'Ecuyer T, Stackhouse PW, Lebsock M, Andrews T (2012) An update on Earth's energy balance in light of the latest global observations. Nat Geosci 5:691-696

Sun Y, Solomon S, Dai A, Portmann R (2007) How often will it rain? J Clim 20:4801-4818. doi:10.1175/ JCLI4263.1

Thompson DWJ, Wallace JM, Hegerl GC (2000) Annular modes in the extratropical circulation. Part II: trends. J Clim 13:1018-1036

Trenberth KE, Fasullo JT (2013) An apparent hiatus in global warming? Earth's Future. doi:10.1002/ 2013EF000165

Trenberth KE, Fasullo JT, Kiehl J (2009) Earth's global energy budget. Bull Am Meteorol Soc 90:311-323. doi:10.1175/2008BAMS2634.1

Wang J-J, Adler RF, Huffman GJ, Bolvin D (2014) An updated TRMM composite climatology of tropical rainfall and its validation. J Clim 27:273-284

Wang J, Dai A, Mears C (2016) Global water vapor trend from 1988 to 2011 and its diurnal asymmetry based on GPS, radiosonde, and microwave satellite measurements. J Clim 29:5205-5222

Wentz FJ (1997) A well-calibrated ocean algorithm for special sensor microwave/imager. J Geophys Res 102(C4):8703-8718

Xie P, Arkin PA (1997) Global precipitation: a 17-year monthly analysis based on gauge observations, satellite estimates, and numerical model outputs. Bull Am Meteorol Soc 78:2539-2558. doi:10.1175/ 1520-0477(1997)078,2539:GPAYMA.2.0.CO;2

Xie S-P, Deser C, Vecchi GA, Ma J, Teng H, Wittenberg AT (2010) Global warming pattern formation: sea surface temperature and rainfall. J Clim 23:966-986

Yu J-Y, Zou Y, Kim ST, Lee T (2012) The changing impact of El Nino on US winter temperatures. Geophys Res Lett 39:L15702. doi:10.1029/2012GL052483 